J.Lake Sci. (湖泊科学), 2016, 28(1): 141-148

DOI 10. 18307/2016. 0116

(C) 2016 by Journal of Lake Sciences

\title{
采用倒置显微镜法定量浮游植物的数据稳定性
}

\author{
牛海玉 ${ }^{1}$, 肖利娟 ${ }^{1,2}$, 韩博平 ${ }^{1,2}$ ** \\ (1:暨南大学生态学系,广州 510632) \\ (2: 广东省水库蓝藻水华防治中心, 广州 510632)
}

\begin{abstract}
摘 要: 浮游植物种类组成细胞密度或生物量的现存量反映其在水生生态系统的结构与功能, 准确地对水体中浮游植物 进行定量是水质评价和生态功能分析的基础. 针对目前国际上推荐使用的倒置显微镜法 (即 Utermöhl 计数法), 通过采集 处于不同营养状态和水体条件 (水库和实验围隔) 中的浮游植物, 分析样品的显微计数量、水体营养状态对浮游植物密度 和多样性等指标稳定性的影响, 同时比较了多个水体中同一采样点的重复 (或平行) 样品之间浮游植物定量数据的差别, 从而对倒置显微镜法进行较为系统的评估. 结果表明, 基于浮游植物的显微镜计数效率与定量数据稳定性的综合考虑, 选 择计数 400 个个体即可基本保证定量数据的稳定性; 在依赖生物量或稀有种进行水质评价时, 处于不同营养水平的水体 均需要增加样品的平行数来提高定量数据的可靠性, 贫营养型水体中单个采样的重复或平行样品更为必要; 两种定量方 法所得群落数据计算的辛普森指数无显著差异, 说明两种方法所获得结果均能反映浮游植多样性; 通过样品浓缩法和倒 置显微镜法所获得的浮游植物生物量和细胞密度均具有显著差异, 因样品浓缩法在样品处理过程中造成浮游植物损失, 使通过样品浓缩法所得的浮游植物群落生物量及细胞密度偏小; 相比浓缩法, 倒置显微镜法沉淀浓缩的水样体积小, 样 品处理和计数耗时短, 更适宜用于应急监测.
\end{abstract}

关键词: 浮游植物; 倒置显微镜计数; 细胞密度;生物量;多样性

\section{Data quality analysis of phytoplankton counted with the inverted microscopy-based meth- od}

\author{
NIU Haiyu ${ }^{1}$, XIAO Lijuan ${ }^{1,2}$ \& HAN Boping ${ }^{1,2 * *}$ \\ (1: Department of Ecology, Jinan University, Guangzhou 510632, P.R.China) \\ (2: Guangdong Center for Protection and Control of Cyanobacterial Blooms in Reservoirs, Guangzhou 510632, P.R.China)
}

\begin{abstract}
Phytoplankton standing stock largely characterizes the structure and function of aquatic ecosystems and thus, it needs to be well quantified for measuring the ecological function. Inverted microscopy method (i.e. Utermöhl's counting method) has been widely applied, but not in developing countries limited by investment for inverted microscopy. Phytoplankton samples collected from three reservoirs with distinct trophic states and three treatments of experimental enclosures were used to demonstrate data quality in using the method. The potential effects of the counting individual and cell abundance, community biomass and cell density in replicates of water samples on the data quality were statistically analyzed. As suggested in the original method by Lund (1958), counting 400 individuals for each plate of meso-and eutrophic water sample is required to balance the stability of data, but we found counting 500 individuals for oligotrophic water is needed. When collecting replicate water samples is possible, especially those used for assessing the water quality, three or five replicates of water samples are strongly suggested to be collected to reduce the standard deviation, especially in oligotrophic water. There was no significant difference in Simpson index between two quantitative methods, indicating that both methods have resulted in a similar measurement of phytoplankton diversity. There were significant differences in both measured biomass and cell density between the two methods because of cells loss during concentrating samples. Compared to the concentrated water sample-based method, inverted microscopy method takes a shorter total time for counting and sedimentation, and is preferred for use in the emergency monitoring.
\end{abstract}

* 水利部河湖健康评估广东省试点项目 (2013001) 和国家自然科学基金项目(U0733007) 联合资助.2015-03-16 收 稿; $2015-05-13$ 收修改稿.牛海玉 (1990 ),女,硕士研究生;E-mail : niuniu-nhy@ 163.com.

** 通信作者; E-mail:tbphan@ jnu.edu.cn. 
Keywords: Phytoplankton; Utermöhl method; cell density ; biomass; richness

浮游植物是水域生态系统中重要组成部分, 其数量与种类多样性是水质监测和评价的重要指标 ${ }^{[-3]}$. 在 每种浮游植物具有相同物理性质情况下, 理论上我们从采集一定体积的水样经固定浓缩后在显微镜下计 数, 然后根据浮游植物细胞的形态按最近似的几何形态测量必要的量度, 可以较为准确地计算出浮游植物 的体积和生物量, 这正是传统浓缩法的原理 ${ }^{[4-6]}$. 然而由于不同种类的浮游植物具有相同物理性质这一假设 通常难以满足, 特别是对于贫营养水体的种类多样性很高时, 浮游植物的个体之间细胞大小、形态与比重相 差很大, 计数过程中的随机取样具有偏向性, 导致最终计算的浮游植物细胞密度与生物量有很大偏差, 种类 丰富度和多样性指数也存在明显的偏差, 当这些数据用于群落分析与水质比较时难以保障结论的可靠性 ${ }^{[7]}$. 陈纯等系统地分析了浮游植物定量过程中生物量计算可能产生的误差 ${ }^{[8]}$, Zarauz 等比较分析了活体样品与 加固定剂样品在生物量上的差别 ${ }^{[9]}$. 样品浓缩法经过沉淀、浓缩、再随机取样镜检等多个步骤方能完成计数 工作, 每一步骤都会产生误差, 并耗时较长. 针对传统的样品浓缩法存在的问题, Utermöhl 提出了倒置显微镜 计数方法, 也称为沉淀杯方法或 Utermöhl 计数法 ${ }^{[10]}$. 从 1978 年起联合国教科文组织将倒置显微镜计数方法 编人浮游植物手册, 该方法已成为国际上浮游植物计数和种类调查的常规方法. 在理论上, 倒置显微镜计数 方法是对原水进行显微镜计数, 减少了浓缩过程的损失, 可提供较好的数据质量. 由于需要倒置显微镜和特 殊的沉淀杯等限制, 多数发展中国家仍以传统的浓缩法为主 ${ }^{[11]}$. 由于对倒置显微镜法的使用还十分有限, 多 数计数人员对该方法及基于该方法所获得的数据可靠性缺少了解, 也是限制该方法在我国推广的一个因素.

在倒置显微镜计数方法中, 通过在计数杯中直接沉淀达到浓缩的目的. 先将鲁哥试剂固定的水样摇匀后 注人沉降管中, 盖好盖玻片静置沉淀, 静置时间在 $24 \mathrm{~h}$ 以上 ${ }^{[12-13]}$, 或根据使用的沉降管的高度选择静置时 间, 确保藻细胞完全沉降, 静水状态下微小浮游植物下沉 $1 \mathrm{~cm}$ 需要 $4 \mathrm{~h}^{[14]}$. 再将沉淀好的水样上清液移除, 盖好盖玻片 (不能有气泡), 在倒置显微镜下计数沉淀在计数杯底座载玻片上的浮游植物 ${ }^{[10]}$. Lund 等针对沉 淀杯体积建议了沉淀时间: $100 \mathrm{ml}$ 需沉淀 $18 \mathrm{~h}, 10 \mathrm{ml}$ 需沉淀 $3 \mathrm{~h}, 1 \mathrm{ml}$ 需沉淀 $1 \mathrm{~h}^{[14]}$. 而Willén 推荐的沉淀时 间则较长 ${ }^{[15]}$.

本研究的水样采集于 3 座不同营养水平水库的敞水区以及 3 种不同处理组的实验围隔, 这些样品提供 了多样化的浮游植物群落类型. 本文对沉淀浓缩过程在浮游植物定量结果中的影响进行分析, 为采用倒置显 微镜法的人员和实验室了解和掌握该方法在沉淀体积、沉淀时间、计数个体数等具体操作以及改善数据可 靠性等方面提供参考.

\section{1 材料与方法}

\section{1 采样地点与采样方法}

浮游植物定量样品采集于 3 个不同营养水平的大型水库及 3 组不同处理的实验围隔, 3 座水库分别为 广东省广州市从化区处于贫中营养水平的流溪河水库 $\left(23^{\circ} 45^{\prime} \mathrm{N}, 113^{\circ} 46^{\prime} \mathrm{E}\right)$ 、广东省茂名市处于中营养水平 的高州水库 $\left(22^{\circ} 2^{\prime} \mathrm{N}, 111^{\circ} 1^{\prime} \mathrm{E}\right)$ 和广东省江门市处于富营养水平的大沙河水库 $\left(22^{\circ} 30^{\prime} \mathrm{N}, 112^{\circ} 21^{\prime} \mathrm{E}\right)^{[16]}$. 实验 围隔 3 个处理组分别为添加营养盐组、添加鱼类组和 1 个对照组, 每个处理组均有 5 个平行, 每个实验围隔 的体积为 $90 \mathrm{~m}^{3[17]}$.

于 2013 年 5 月对 3 座水库进行一次性定量分析样品的采集, 同时测定了水体的相关理化指标及叶绿素 $\mathrm{a}$ 浓度 ${ }^{[18]} .3$ 座水库浮游植物定量分析样品用采水器在敞水区表层 $0.5 \mathrm{~m}$ 处采得, 采集水样的体积为 $10 \mathrm{~L}$, 混 合均匀后分装 $350 \mathrm{ml}$ 和 $1000 \mathrm{ml}$ 聚乙烯塑料瓶各 5 个. $350 \mathrm{ml}$ 的 5 瓶水样编号为 $\mathrm{a} 、 \mathrm{~b} 、 \mathrm{c} 、 \mathrm{~d} 、 \mathrm{e}$, 每瓶加 $3.5 \mathrm{ml}$ 鲁哥试剂固定, 采用倒置显微镜法进行定量计数; 5 个 $1000 \mathrm{ml}$ 水样加福尔马林试剂固定, 采用样品浓缩法进 行定量计数. 2013 年 7 月对 15 个实验围隔进行一次性采样, 每个围隔在表层 $0.5 \mathrm{~m}$ 处采集 $350 \mathrm{ml}$ 水, 每瓶水 样加 $3.5 \mathrm{ml}$ 鲁哥试剂固定, 以待下一步的沉淀浓缩和镜检.

鲁哥试剂配方: $20 \mathrm{~g} \mathrm{KI}$ 和 $10 \mathrm{~g} \mathrm{I} \mathrm{I}_{2}$ 溶于 $200 \mathrm{ml}$ 蒸馏水 ${ }^{[10]}$.

\section{2 样品处理及计数方法}

所有水样的处理和计数方法保持一致. 根据水库的营养水平选择沉淀杯体积: 流溪河水库的样品选择 
$50 \mathrm{ml}$ 沉淀杯, 静置沉降 $15 \mathrm{~h}$; 高州水库的样品选择 $10 \mathrm{ml}$ 沉淀杯, 静置沉淀 $3 \mathrm{~h}$; 大沙河水库的样品选择 $3 \mathrm{ml}$ 沉淀杯, 静置沉淀 $1.5 \mathrm{~h}$; 围隔样品选择 $10 \mathrm{ml}$ 沉淀杯, 静置沉淀 $3 \mathrm{~h}$. 通过静置沉淀浓缩后, 移去沉降管及里面 的清液, 将浓缩在计数框底座载玻片上的浮游植物在倒置显微镜下进行计数.

将计数框底座载玻片置于倒置显微镜下进行浮游植物镜检和计数. 首先在 $10 \times 10$ 倍镜下对载玻片上所 有体积较大的浮游植物 (>20 $\mu \mathrm{m}$ ) 进行计数; 然后在 10×40 倍镜下对较小浮游植物 (2 20 $\mu \mathrm{m}$ ) 进行计数, 计 数的视野数量以能计数 500 个个体为止, 同时计数时将这 500 个个体分为 5 个 100 的计数段, 且保证视野在 载玻片上均匀分布 ${ }^{[9]}$. 在计数过程中, 如碰到某些个体一部分在视野中, 部分在视野外, 可只对出现在视野上 半圈的浮游植物计数, 而出现在下半圈的浮游植物不计数, 如全部计数会导致定量结果偏高 ${ }^{\left[{ }^{[}\right]}$. 采用 5 种个 体计数等级: 1 代表 100 个个体计数量, 即从用上述方法在 $10 \times 40$ 倍下计数的 5 个 100 的计数段中随机抽取 一个计数段的个体; 2 代表 200 个个体计数量, 即从用上述方法在 $10 \times 40$ 倍镜下计数的 5 个 100 的计数段中 随机抽取 2 个计数段的个体; 3 代表 300 个个体计数量, 即从用上述方法在 $10 \times 40$ 倍镜下计数的 5 个 100 的 计数段中随机抽取 3 个计数段的个体; 4 代表 400 个个体计数量, 即从用上述方法在 $10 \times 40$ 倍镜下计数段中 随机抽取 4 个计数段的个体; 5 代表 500 个个体计数量, 即从用上述方法在 $10 \times 40$ 倍镜下计数 5 个计数段的 个体. 在 $10 \times 40$ 倍下计数的个体计算出密度加上在 $10 \times 10$ 倍镜下进行整片计数的细胞密度即样品的细胞密 度, 每个样品有 5 种计数等级产生的细胞密度值, 即 $\mathrm{a} 1 \sim \mathrm{a} 5 、 \mathrm{~b} 1 \sim \mathrm{b} 5 、 \mathrm{c} 1 \sim \mathrm{c} 5 、 \mathrm{~d} 1 \sim \mathrm{d} 5 、 \mathrm{e} 1 \sim \mathrm{e} 5$.

\section{3 浮游植物鉴定和群落细胞密度、群落生物量及辛普森多样性指数计算}

浮游植物种类鉴定主要参照有关文献的描述及图鉴 ${ }^{[19]}$.

基于倒置显微镜法, 每个样品分别镜检 5 个计数段的浮游植物, 并分别计算镜检每个计数段所对应的 细胞密度.藻细胞密度计算公式为:

$$
N=\frac{C \cdot D^{2}}{V \cdot n \cdot d^{2}}
$$

式中, $N$ 为原水的藻细胞密度 $(\mathrm{cells} / \mathrm{ml}), V$ 为沉降水样的体积 $(\mathrm{ml}), D$ 为载玻片直径 $(\mathrm{mm}), d$ 为计数镜头直 径 $(\mathrm{mm}), n$ 为计数镜头数, $C$ 为计数细胞数 ( cells).

在常见的浮游植物生物量计算方法中, 可归纳为 4 种不同的生物量计算方法: 标准法、细分法、粗分法 和资料法 ${ }^{[20-21]}$. 粗分法克服了细分法繁琐耗时的缺陷, 在保证数据具有较高可靠性的前提下有效节省了时间 和人力, 是计算浮游植物生物量的高效方法, 所以在本研究中两种定量方法均采用粗分法进行生物量 计算 ${ }^{[8]}$.

计算镜检每个计数段所对应的浮游植物群落辛普森多样性指数 (Simpson's diversity index, $D$ ), 测定各水 库中镜检每个计数段所对应的浮游植物群落物种多样性. 计算公式为:

$$
D=1-\sum\left(\frac{N_{i}}{N}\right)^{2}
$$

式中, $N_{i}$ 为 $i$ 物种的个体数, $N$ 为总个体数 ${ }^{[22]}$.

\section{4 浮游植物定量数据的均值及偏差计算}

用随机选择 $\mathrm{a} 1$ 有 $\mathrm{C}_{5}^{1}$ 即 5 种结果, 选取其中 4 个值计算 $\mathrm{a} 1$ 的均值和偏差, 同理计算 $\mathrm{a} 2 \sim \mathrm{a} 4$ 的均值和偏 差. 得出各 $1 、 2 、 3 、 4$ 计数段对应的各定量数据的平均值及偏差. 采用群落多样性稀疏方法 (rarefaction) 提供对 不同平行样品 $(\mathrm{a} \sim \mathrm{e})$ 所代表的群落结构进行比较. 所有计算在 $\mathrm{R}$ 语言中实现 ${ }^{[23]}$.

\section{2 结果与分析}

\section{1 不同计数量的浮游植物细胞密度、生物量与群落多样性}

对计数量为随机化抽取的 $\mathrm{a} 1 、 \mathrm{a} 2 、 \mathrm{a} 3 、 \mathrm{a} 4 、 \mathrm{a} 5$ 定量数据进行比较, 发现浮游植物细胞密度随着计数个体数 的增加趋于稳定, 偏差减小 (图 1). 计数 $\mathrm{a} 4$ 的生物量数据基本趋于稳定, 且偏差相对 $\mathrm{a} 1 、 \mathrm{a} 2 、 \mathrm{a} 3$ 、平行所得数 据偏差较小 (图 1). 计数量与浮游植物种类数偏差呈负相关性, 即随计数量的增加, 浮游植物种类数偏差降 低(图 2). 

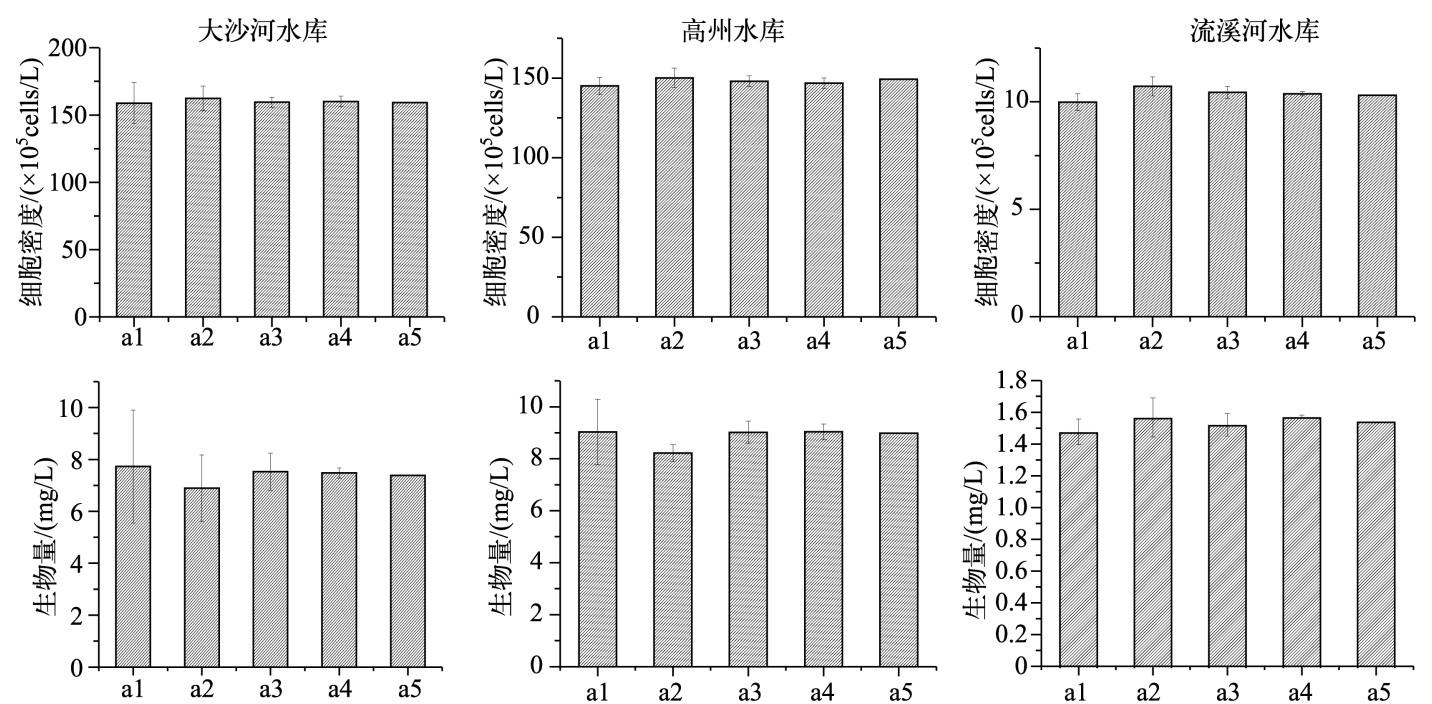

图 1 不同计数量下浮游植物丰度与生物量的比较

Fig. 1 Cell density and biomass of phytoplankton under different counting individuals
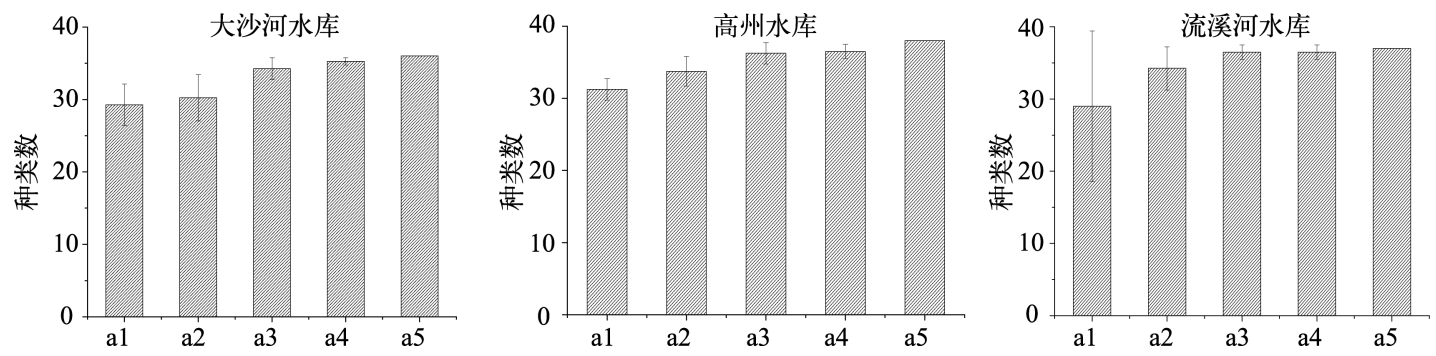

图 2 不同计数量下浮游植物种类数的比较

Fig.2 Observed species richness of phytoplankton under different counting individuals

\section{2 平行水样浮游植物定量的重复性}

根据 2.1 节数据分析, 每个水样计数 4 个计数段时生物量、细胞密度和种类丰富度接近计数 5 个计数段 个体下的值, 并且数据偏差比计数 $1 、 2 、 3$ 个计数段的偏差小. 因此, 在 Lund 等推荐的这一计数量 ( 400 个体) 下,进行不同水库同一采样点的平行水样定量结果比较 (图 3), 3 座水库的 5 个平行样品之间的细胞密度、 生物量、辛普森指数都有较大差别. 单个 (瓶) 浮游植物样品的细胞密度与 5 个 (瓶) 浮游植物样品的平均细 胞密度之间最大相差 $24.36 \%$; 单个 (瓶) 浮游植物样品的生物量与 5 个 (瓶) 浮游植物样品的平均生物量之 间最大相差 $70.38 \%$; 浮游植物群落辛普森指数最大相差 $37.13 \%$.

图 4 给出了 3 座水库各自计数 4 个计数段及计数 5 个计数段所对应的浮游植物群落种类稀疏曲线, 它 们提供不同样品所对应群落结构的比较. 计数细胞数不同时, 观测到的浮游植物种类不同. 两座营养水平较 高的水库 (大沙河水库和高州水库) 计数 4 个计数段和计数 5 个计数段所观测到的种类数基本达到稳定, 而 营养水平较低的流溪河水库中计数 4 个计数段和计数 5 计数段所观测到的种类数均未达到渐进线.

\section{3 细胞密度、生物量与数据质量}

对计数 400 个个体的浮游植物定量数据进行偏差分析, 以了解浮游植物细胞密度和生物量对定量数据 偏差的影响分析. 生物量偏差与浮游植物细胞密度、生物量之间均有显著相关性 (图 5). 水体浮游植物细胞 密度的高低对定量计数结果的稳定性有着较为明显的影响, 细胞密度越高, 定量计数结果数据稳定性越低. 浮游植物生物量与生物量偏差有显著正相关性, 说明浮游植物生物量越高, 定量计数结果的稳定性越低. 

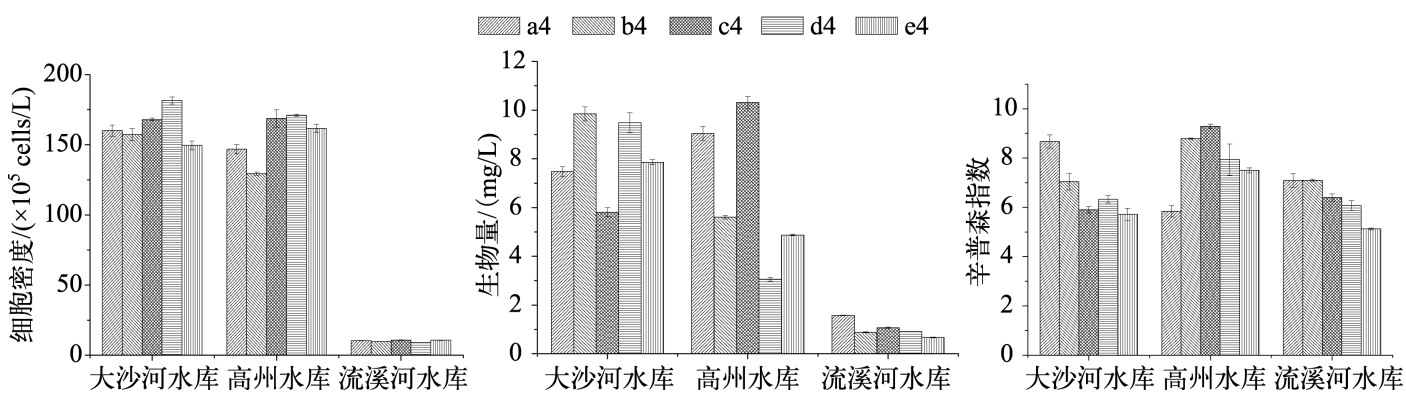

图 3 每个样品计数 400 个个体下各水库的 5 个平行样品中浮游植物细胞密度、生物量、辛普森指数

Fig. 3 Cell density, biomass and Simpson index of phytoplankton from three reservoirs under counting 400 units
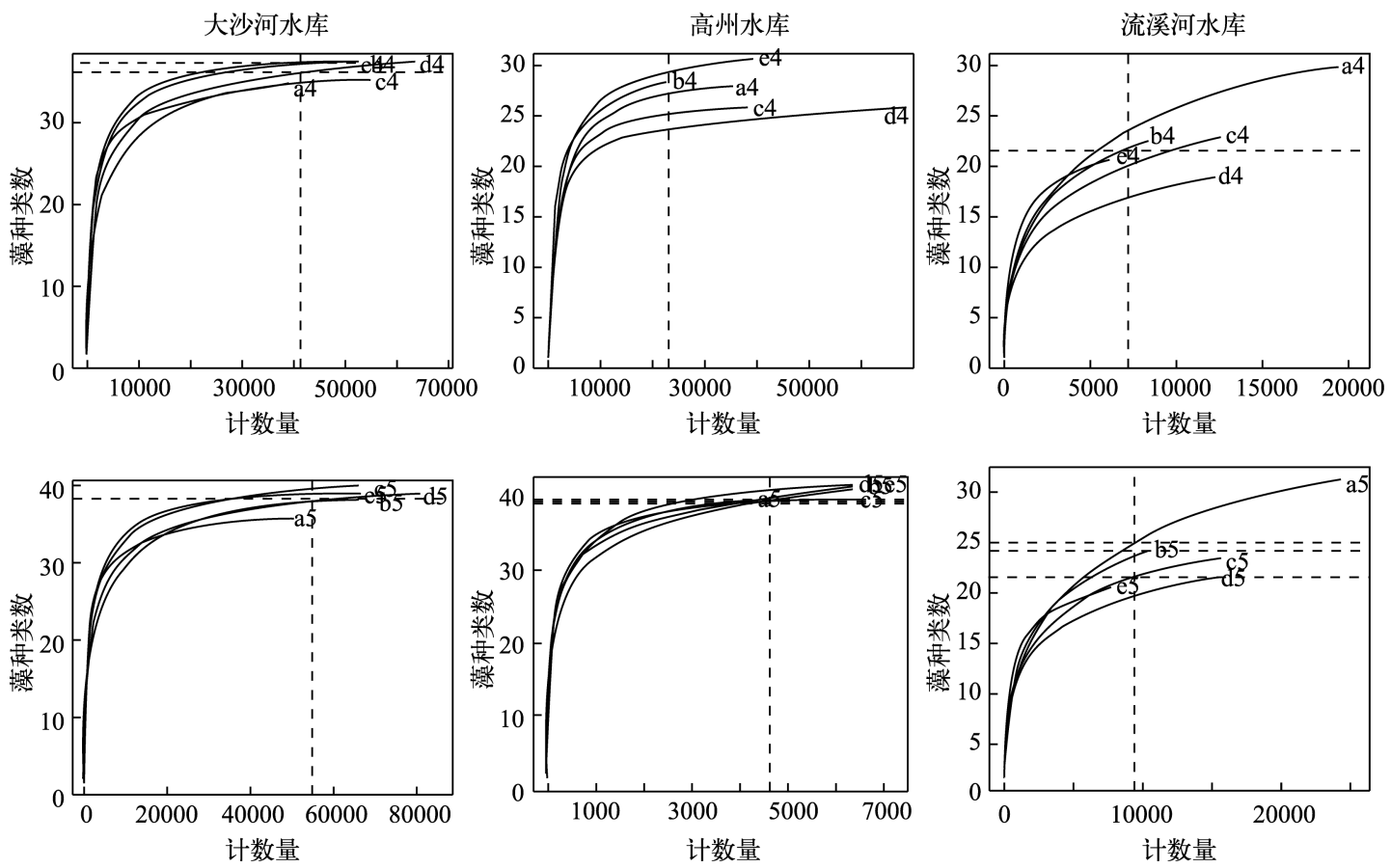

图 43 座水库平行水样分别计数 400 个体 $(\mathrm{a} 4 \sim \mathrm{e} 4)$ 及计数 500 个体 $(\mathrm{a} 5 \sim \mathrm{e} 5)$

时所对应的浮游植物群落种类稀疏曲线

Fig.4 Rarefaction curves of species richness in five repeated water samples from three reservoirs with distinct trophic states under counting $400(\mathrm{a} 4-\mathrm{e} 4)$ and 500 individuals (a5 - e5)

\section{4 样品浓缩法及倒置显微镜法的数据对比}

根据样品浓缩法相关文献及上文结论, 对倒置显微镜法计数 400 个个体及样品浓缩法计数 4 片平行的 定量数据进行对比分析 (one-way ANOVA), 两种定量计数方法所得的生物量数据有显著差异 ( $P_{\text {流深河水库 }}<$ $\left.0.001, P_{\text {高州水库 }}<0.001, P_{\text {大沙河水库 }}<0.001\right)$; 两种定量数据方法所得的浮游植物细胞密度数据有显著差异 $\left(P_{\text {流添河水库 }}<0.001, P_{\text {高州水库 }}<0.005, P_{\text {大沙河水库 }}<0.001\right)$; 两种定量方法所得的辛普森指数无显著差异 $\left(P_{\text {流深河水库 }}=\right.$ $\left.0.551, P_{\text {高州水库 }}=0.601, P_{\text {大沙河水库 }}=0.812\right)$. 样品浓缩法所得的浮游植物生物量和细胞密度要小于倒置显微镜 法计算所得的生物量和细胞密度,但两种方法得到的辛普森指数相近 (图 6). 

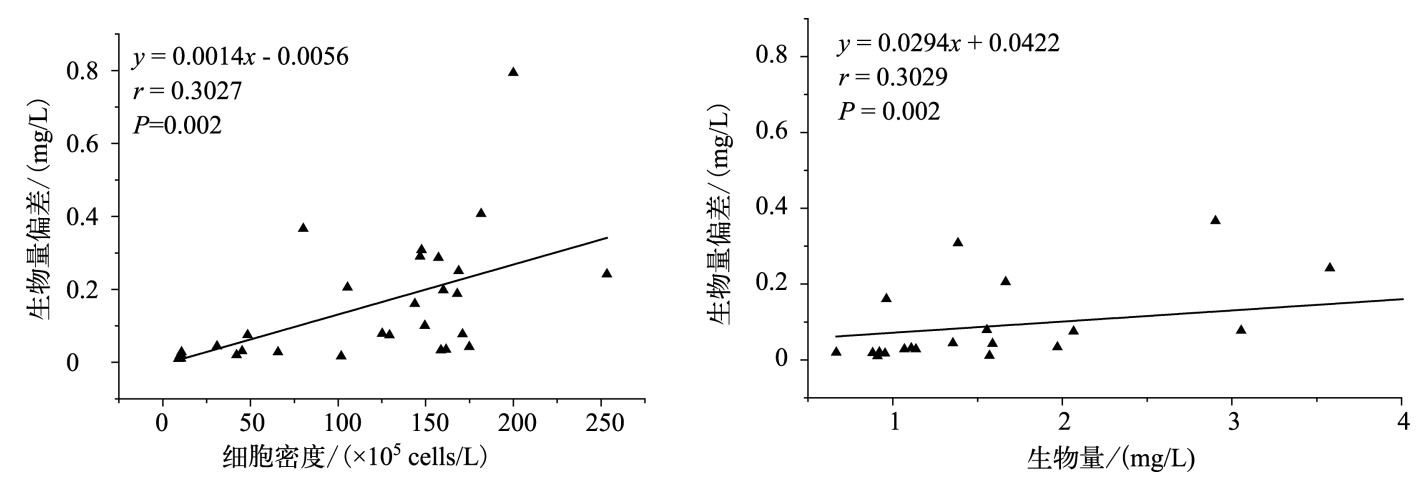

图 5 浮游植物生物量偏差与样品细胞密度及生物量的回归关系

Fig.5 Relationships between data quality (standard deviation) and the total counting cell density and biomass

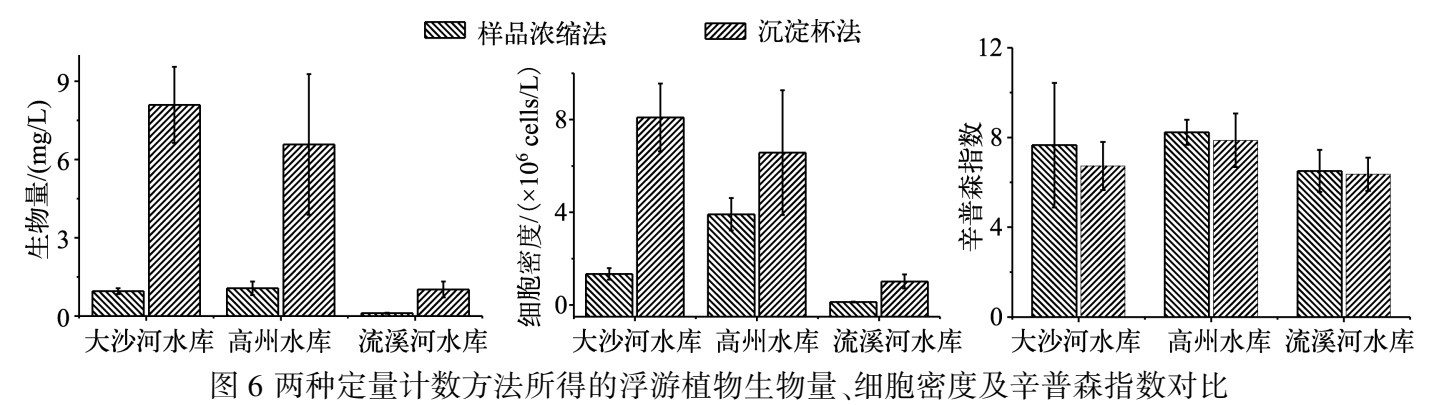

Fig. 6 Comparison of biomass, cell density and Simpson index of three phytoplankton communities counted by two methods

\section{3 讨论}

\section{1 计数量对浮游植物细胞密度、生物量与群落多样性的影响}

倒置显微镜法的计数量控制为在 $10 \times 40$ 倍镜下镜检不少于 400 个个体即可 ${ }^{[24]}$. 本研究采用的是 $10 \times 10$ 倍下镜检整片浮游植物计数板, $10 \times 40$ 倍镜下随机选取视野镜检多于 400 个个体. $10 \times 10$ 倍镜下镜检整片浮 游植物计数板可以减少大个体浮游植物及稀有种无法被镜检的概率, 稀有种对定量结果影响较大, 因此 $10 \times$ 10 倍下镜检整片浮游植物计数板非常必要 ${ }^{[8]}$.

在本文计数方法下, 浮游植物计数个体数的增加对定量数据的影响并不明显, 但在一定范围内随计数 个体数的增加可检出更多种类, 浮游植物细胞密度和生物量偏差均减小, 所以镜检计数的个体数增加可使 定量结果更加接近真实值并提高定量结果的可信度. 但本文数据分析表明,一般情况下计数 400 个个体即可 使细胞密度、生物量的偏差较小, 从而保证数据的稳定性和可靠性.

\section{2 平行样品数与浮游植物定量偏差的关系}

在实际研究中经常出现不同研究人员在相同时间、同一水体、同一地点采样测得的数据有较大偏差的 现象. 造成这种偏差的原因可能有多方面, 其中计数方法和样品平行性差异被认为是主要的. 浮游植物群落 的特点, 如密度、生物量也是影响生物量偏差的重要因素. 密度和总生物量的提高会增加这类偏差, 说明浮游 植物密度越高的水体由单个样品计数计算出的浮游植物定量数据不稳定性也越高. 倒置显微镜法所镜检的 样品未经虹吸浓缩和浓缩液转移处理, 理论上所得的定量数据能够相对准确地反映出浮游植物现存量. 但在 浮游植物种类较多的情况下, 倒置显微镜法所鉴定出的浮游植物种类数可能会低于样品浓缩法所鉴定出的 种类数. 倒置显微镜法对一些自然水体中稀有浮游植物种类的检测不够, 倒置显微镜法一次镜检的最大水样 
体积是 $100 \mathrm{ml}$, 并且根据营养水平的增加减少沉淀镜检样品体积, 这样会造成镜检到稀有种的概率降低 ${ }^{[14]}$. 稀疏曲线提供分析和比较不同样品种类数的方法, 这种方法在开展多样性分析时更为有效. 从我们对采样水 库平行样品之间的比较来看, 样品的可重复性因水体的性质变化而变化, 贫营养水体样品重复性相对较低. 导致平行样品定量数据之间存在差别的原因,一方面与水样之间的可重复性有关, 另一方面与沉淀过程的 可重复性有关. 为此可以通过增加镜检平行样品的方法来弥补种类多样性方面研究的不足. 为提高浮游植物 定量数据的可靠性, 在条件允许的情况下采集平行样品是必要的, 可靠的水质等级评价和划分更需要以足 够的平行水样来保证数据质量和评价结果的可靠性.

\section{3 沉淀体积及时间的确定}

为保证不影响正常镜检, 避免藻类重叠而影响计数, 倒置显微镜法的沉淀体积需根据待检测水样的营 养水平及藻细胞密度而定, 塞中营养水平水体沉淀 $50 \mathrm{ml}$ (如流溪河水库), 中营养水平水体沉淀 $10 \mathrm{ml}$ (如高 州水库), 中富营养水平水体沉淀 $3 \mathrm{ml}$ (如大沙河水库). 为了避免计数框高沉降柱对浮游植物细胞的黏附作 用引起的误差, 尽量减少使用 $100 \mathrm{ml}$ 的高沉降柱 ( $20 \mathrm{~cm}$ 高), 可通过增加计数个体数来提高数据质量.

Lund 等推荐的沉淀时间为: $100 \mathrm{ml}$ 沉淀 $18 \mathrm{~h}, 10 \mathrm{ml}$ 沉淀 $3 \mathrm{~h}, 1 \mathrm{ml}$ 沉淀 $1 \mathrm{~h}^{[14]}$. 而 Willén 则推荐: $10 \mathrm{ml}$ 沉 淀 $8 \mathrm{~h}, 50 \mathrm{ml}$ 或 $100 \mathrm{ml}$ 沉淀 $48 \mathrm{~h}^{[15]}$. 但对于不同水体强行要求沉淀时间并不合适, 应根据观测目的和水样的 不同适当调整沉降时间 ${ }^{[10]}$. 另外, 通过鲁哥试剂染色的浮游植物细胞重量会增加, 沉降速率也有所增加, 可 适当减少沉降时间以便提高监测效率.

\section{4 样品浓缩法及倒置显微镜法的对比}

两种定量计数方法计算所得的辛普森指数无显著差异, 说明两种方法所得结果均能反映浮游植物群落 结构的整体指标. 但样品浓缩法通过沉淀、浓缩、再随机取样镜检等多个步骤方能完成计数工作,每一步都有 误差产生. 样品浓缩法一般取 $1000 \mathrm{ml}$ 样品在聚乙烯瓶中静置沉淀后再进行虹吸浓缩, $1000 \mathrm{ml}$ 聚乙烯瓶的 内壁面积及沉淀高度远高于沉淀杯的沉降柱内壁面积及沉淀高度, 因此样品浓缩法在沉降过程、虹吸过程 无法避免浮游植物的损失, 使通过样品浓缩法所得的浮游植物群落生物量及细胞密度与倒置显微镜法相比 偏小.

倒置显微镜法中使用的 Utermöhl 计数框密封性较好, 水分蒸发对浮游植物计数的准确性基本无影响. 对 样品浓缩法而言, 为避免水分蒸发的影响, 则要求计数者对每片样品的计数在 $1 \mathrm{~h}$ 内完成. 浓缩法监测规范 通常要求计数 2 片平行, 但 4 片平行才能保证定量结果的稳定性 ${ }^{[7]}$, 然而采用倒置显微镜法计数 400 个体通 常需要 $2 \mathrm{~h}$ 左右. 由此可见, 倒置显微镜法与传统样品浓缩法相比, 沉淀及计数时间都较短, 更适合用于水华 暴发等临时性应急水质监测.

\section{4 结论}

1) 倒置显微镜法对原水样进行镜检时, 减少了浓缩及取样过程中产生的误差, 能够较准确地计数. 倒置 显微镜法计数通过增加计数个体数可提高定量数据的稳定性,计数 400 个个体时数据基本稳定.

2) 浮游植物样品的沉淀体积要根据水体的营养水平及浮游植物细胞密度而定, 为不影响镜检计数可行 性和减少高沉降柱带来的误差, 建议寡营养水体选择 $50 \mathrm{ml}$ 沉淀杯, 中营养水体选择 $10 \mathrm{ml}$ 沉淀杯, 富营养水 体选择 $3 \mathrm{ml}$ 沉淀杯.

3) 倒置显微镜法与传统样品浓缩法相比, 沉淀及计数时间都较短, 更适合用于水华暴发等临时性应急 水质监测.

4) 相比传统的浓缩法,倒置显微镜法采用了统一的计数量,这为方法的统一与标准提供了定量控制,也 为长期观测数据的可比性奠定了基础.

\section{5 参考文献}

[ 1 ] Bianchi F, Acri F, Aubry FB et al. Can plankton communities be considered as bio-indicators of water quality in the Lagoon of Venice? Marine Pollution Bulletin, 2003, 46: 964-971.

[ 2 ] Reynolds CS. Ecology of Plankton. Cambridge: Cambridge University Press, 2006. 
[ 3 ] Richardson TL, Gibson CE, Heaney SI et al. Temperature, growth and seasonal succession of phytoplankton in Lake Baikal, Siberia. Freshwater Biology, 2000, 44: 431-40.

[4] 王 冀, 王 建. 浮游植物的采集、计数与定量方法. 水库渔业, 1982, 4: 58-63.

[ 5 ] 孙 军, 刘东艳, 钱树本. 浮游植物生物量研究 I. 浮游植物生物量细胞体积转化法. 海洋学报, 1999, 1(2): $75-85$.

[ 6 ] Sun J, Liu D. Geometric models for calculating cell biovolume and surface area for phytoplankton. Journal of Plankton Research, 2003, 25(11): 1331-1346.

[ 7 ] 牛海玉, 陈 纯, 韩博平. 基于浓缩法的浮游植物定量数据稳定性与可靠性分析. 湖泊科学, 2015, 27(5): 776782. DOI 10. 18307/2015. 0503.

[ 8 ] 陈 纯, 李思嘉, 胡 韧等. 四种浮游植物生物量计算方法的比较分析. 湖泊科学, 2013, 25(6): 927-935. DOI 10. $18307 / 2013$. 0617 .

[ 9 ] Zarauz L, Irigoien X. Effects of Lugol's fixation on the size structure of natural nano-microplankton samples, analyzed by means of an automatic counting method. Journal of Plankton Research, 2008, 30(11) : 1297-1303.

[10] Edler L, Elbrächter M. The Utermöhl method for quantitative phytoplankton analysis. In: Karlson B, Cusack C, Bresnan E eds. Microscopic and molecular methods for quantitative phytoplankton analysis. Paris: UNESCO, 2010: 110.

[11] 金相灿. 湖泊富营养化调查规范: 第 2 版. 北京: 中国环境科学出版社, 1990: 239-245.

[12] McDermott G, Raine R. Settlement bottle method for quantitative phytoplankton analysis. Microscopic and molecular methods for quantitative phytoplankton analysis. Paris: UNESCO, 2010: 21-24.

[13] Rott E, Salmaso N, Hoehn E. Quality control of Utermöhl-based phytoplankton counting and biovolume estimates-an easy task or a Gordian knot? Hydrobiologia, 2007, 578(1) : 141-146.

[14] Lund JWG, Kipling C, LeCren ED. The inverted microscope method of estimating algal numbers and the statistical basis of estimations by counting. Hydrobiologia, 1958, 11(2) : 143-170.

[15] Willén E. A simplified method of phytoplankton counting. British Phycological Journal, 1976, 11(3) : 265-278.

[16] 林秋奇, 胡 韧, 段舜山等. 广东省大中型供水水库营养现状及浮游生物的响应. 生态学报, 2003, 23(6): 1102-1108.

[17] 陈晓玲, 程 丹, 李慧明等. 南亚热带水库中盔形溞牧食对浮游植物群落影响的围隔试验. 水生态学杂志, 2012, 33(3) : 20-26.

[18] 林少君, 贺立静, 黄沛生等. 浮游植物中叶绿素 a 提取方法的比较与改进. 生态科学, 2005, 24(1): 9-11.

[19] 胡鸿钧, 魏印心. 中国淡水藻类: 系统分类及生态. 北京: 科学出版社, 2006.

[20] Hillebrand H, Dürselen CD, Kirschtel D et al. Biovolume calculation for pelagic and benthic microalgae. Journal of Phycology, 1999, 35(2): 403-424.

[21] 王 骥, 王 建. 浮游植物的叶绿素含量、生物量、生产量相互换算中的若干问题. 武汉植物学研究, 1984, 2(2): 249-258.

[22] Heip C, Engels P. Comparing species diversity and evenness indices. Journal of the Marine Biological Association of the United Kingdom, 1974, 54(3): 559-563.

[23] R Development Core Team. R: A language and environment for statistical computing. R Foundation for Statistical Computing, Vienna, Austria. 2008, ISBN 3-900051-07-0, URL http: //www. R-project. org.

[24] 孙 军, 刘东艳, 钱树本. 一种海洋浮游植物定量研究分析方法 Utermöhl 方法的介绍及其改进. 黄渤海海洋, $2002,20(2): 105-112$. 